\title{
Importance of angina for development of collateral circulation
}

\author{
MASATOSHI FUJITA, SHIGETAKE SASAYAMA, AKIRA OHNO, \\ HISAYOSHI NAKAJIMA, HIDETSUGU ASANOI
}

From the Second Department of Internal Medicine, Toyama Medical and Pharmaceutical University, Sugitani, Toyama, fapan

SUMMARY The extent of collateral circulation in 46 patients who had intracoronary thrombolysis within six hours of the onset of acute myocardial infarction was evaluated. Patients who had had a previous myocardial infarction ( 4 cases) or who had spontaneously recanalised infarct related coronary arteries ( 5 cases) were excluded from the analysis. Collateral development was graded during coronary cineangiography according to the extent of opacification of the collateral and epicardial arteries distal to the site of occlusion (collateral index 0 to 3 ). Angina was considered to be present before myocardial infarction if it had occurred more than one week before acute myocardial infarction. Collateral channels were visible in only two of 19 patients without angina before infarction and nine of the 18 patients with angina before infarction. The prevalence of angina and the collateral index were not significantly influenced by the extent of coronary vessel disease.

It is concluded that myocardial ischaemia is important in promoting collateral development in man as well as in laboratory animals.

When myocardial ischaemia is caused by severe stenosis of a coronary artery it stimulates the development of collateral vessels between major coronary arteries. ${ }^{12}$ Some workers have attempted to relate the extent of the development of collateral channels to pre-infarction angina, which is indicative of myocardial inschaemia. ${ }^{34}$ Collateral perfusion will be less when the diseased arteries are not completely obstructed. ${ }^{5}$ In these circumstances, even if there are well developed collateral vessels, collateral flow and corresponding imaging of the collateral channels may be reduced. ${ }^{6}$ Thus collateral development in patients with myocardial infarction can only be evaluated accurately when the diseased coronary arteries are occluded. We studied patients who were referred for intracoronary thrombolysis within six hours of the onset of a first myocardial infarction. We selected this group because severe myocardial ischaemia caused by coronary occlusion was likely to have pro-

Requests for reprints to Dr Shigetake Sasayama, The Second Department of Internal Medicine, Toyama Medical and Pharmaceutical University, 2630 Sugitani, Toyama 930-01, Japan.

Accepted for publication 16 October 1986 moted the development of collaterals. ${ }^{7-9}$ We studied coronary arteriograms obtained immediately after the onset of the symptoms of acute myocardial infarction to evaluate the effects of myocardial ischaemia on the development of collaterals in these patients.

\section{Patients and methods}

Over a five year period 46 patients with acute myocardial infarction were referred for intracoronary thrombolytic treatment within six hours of the onset of symptoms. The diagnosis of acute transmural infarction was established by the presence of acute chest pain lasting $>30$ minutes and persistent ST segment elevation with or without abnormal $Q$ waves in the standard 12 lead electrocardiogram. We excluded four patients with a history of $Q$ wave infarction and five with subtotal stenosis of an infarct related coronary artery. The remaining 37 patients ( 31 men and 6 women, mean age 62.5 (range 44-79) had occlusion of one of three major coronary arteries. Pre-infarction angina was defined as typical chest pain occurring more than one week before the acute myocardial infarction. Twenty one patients had an 
anterior infarction and 16 had an infarction at other sites. Coronary artery disease $(\geqslant 50 \%$ reduction in luminal diameter) of one, two, or three vessels was found in 18,10, and nine patients respectively (table).

\section{CORONARY CINEARTERIOGRAPHY}

All patients undergoing selective coronary arteriography in multiple projections by Judkins' or Sones' techniques signed consent forms approved by the university ethics committee. We used a 6 inch Toshiba image intensifier and a $35 \mathrm{~mm}$ Ariflex cine camera for arteriography. Two observers who were unaware of the presence or absence of pre-infarction angina in individual patients assessed the cineangiograms and reached a consensus. They classified the degree of opacification of the collateral and epi-
Fujita, Sasayama, Ohno, Nakajima, Asanow $\frac{\text { T/ }}{\frac{1}{D}}$ cardial arteries into four grades (collateral index): 05. none; 1 , filling of side branches of the artery to be: perfused via collateral vessels without visualisation? of the epicardial segment; 2, partial filling of the epicardial segment via collateral vessels; 3 , complete filling of the epicardial segment via collateral vessels

STATISTICAL ANALYSIS

We used the $\chi^{2}$ test to analyse differences between proportions. When necessary we also used Student's $t$ test and analysis of variance. A p value of $<0.050$ was regarded as statistically significant. Results are given as mean (SE).

\section{Results}

Eighteen patients (group 1: 60.2 (2.0) years old) had

Table Data on 37 patients undergoing intracoronary thrombolysis within six hours of the onset of acute myocardial infarction

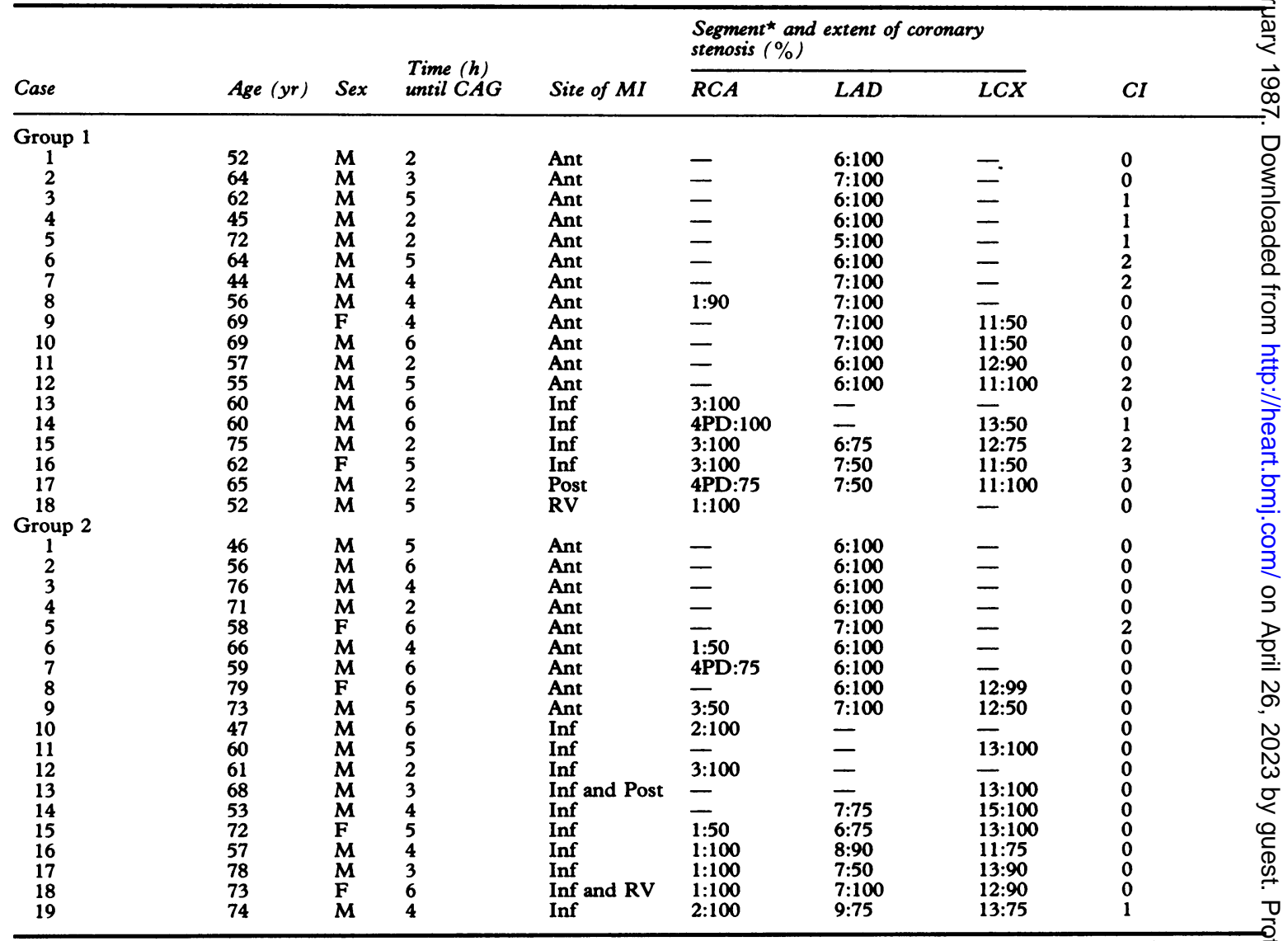

Ant, anterior infarction; CAG, coronary arteriography; CI, collateral index; Inf, inferior infarction; LAD, left anterior descending coronarxD artery; LCX, left circumflex coronary artery; MI, myocardial infarction; PD, posterior descending coronary artery; Post, posteriok infarction; RCA, right coronary artery; RV, right ventricular infarction.

$\star$ Coronary artery segments were identified and categorised according to a reporting system proposed by the American Heart Association. ${ }^{1}$ Group 1 had pre-infarction angina and group 2 did not. 
pre-infarction angina and the remaining 19 patients (group 2, aged 64.6 (2.3)) had not reported angina before infarction (table). Coronary arteriography was carried out $3.9(0.4)$ hours after the onset of acute myocardial infarction in group 1 and $4.5(0.3)$ hours in group 2 (table).

The prevalence of pre-infarction angina was not influenced by the site of infarction. Pre-infarction angina was reported in $12(57 \%)$ of 21 patients with anterior infarction and $\mathrm{six}(38 \%)$ of 16 with infarction at other sites. The proportion of patients with angina was similar whatever the extent of coronary vessel disease $(9 / 18(50 \%)$ in one vessel disease; $6 / 10(60 \%)$ in two vessel disease; $3 / 9(33 \%)$ in three vessel disease).

The presence of pre-infarction angina was the fac-
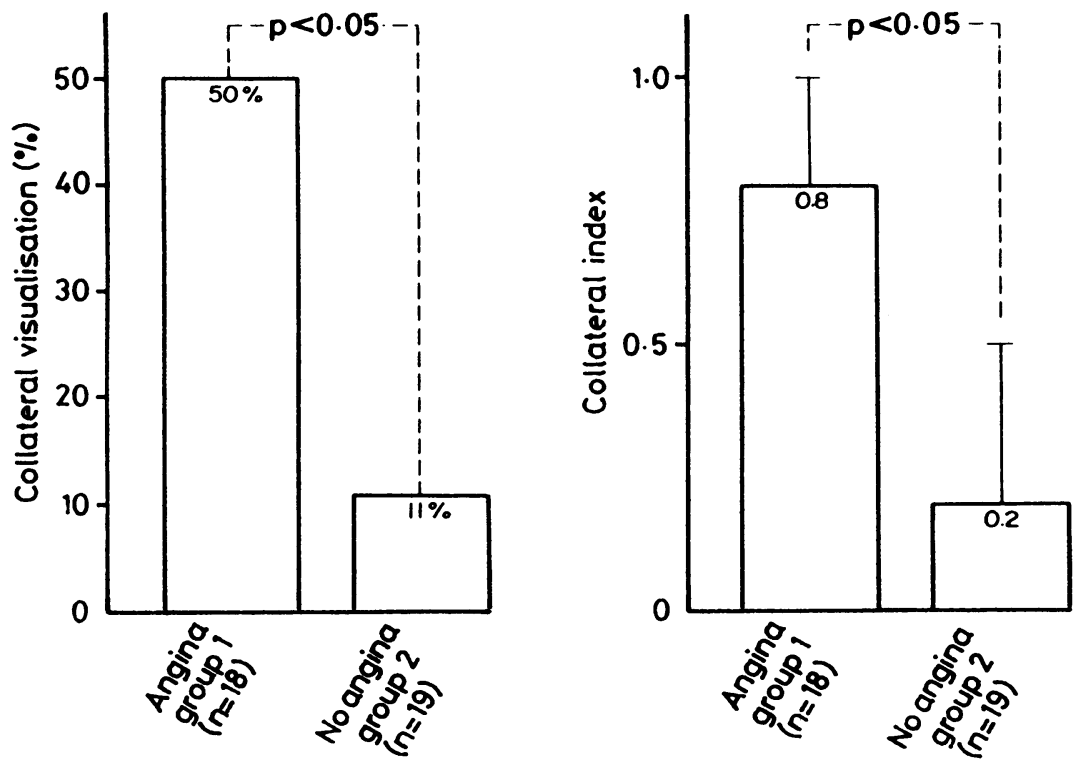

Fig 1 Collateral visualisation and collateral index in patients with or without pre-infarction angina pectoris.
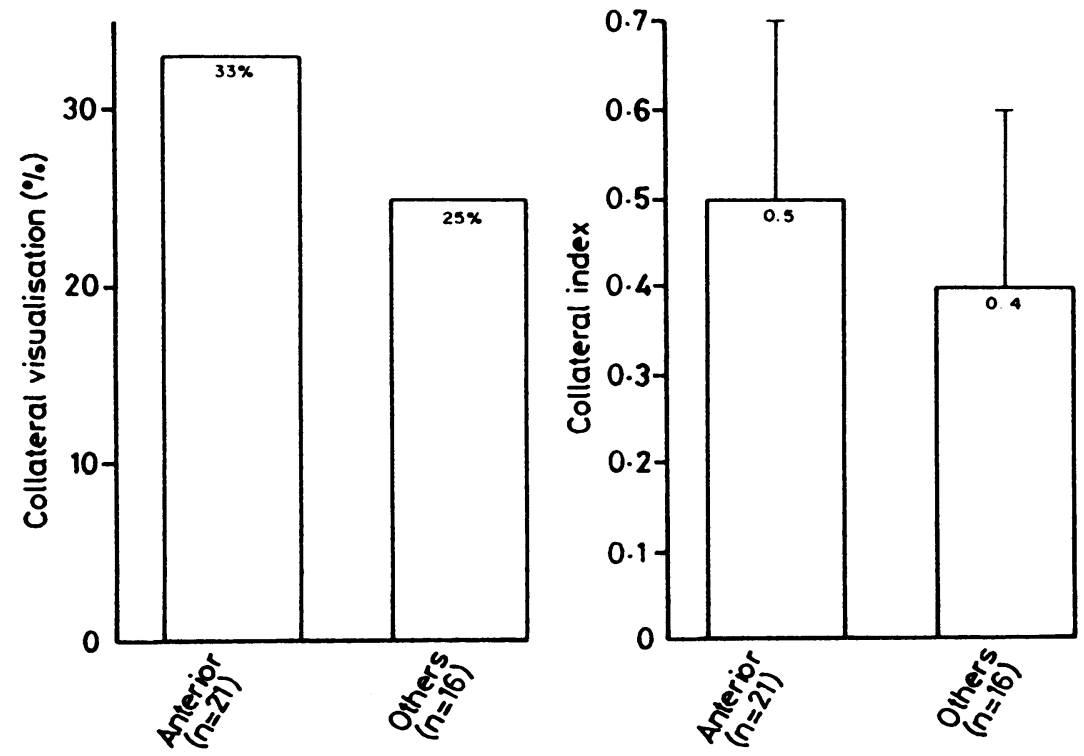

Fig 2 Collateral visualisation and collateral index in patients with anterior infarction and in those with infarction at other sites. 

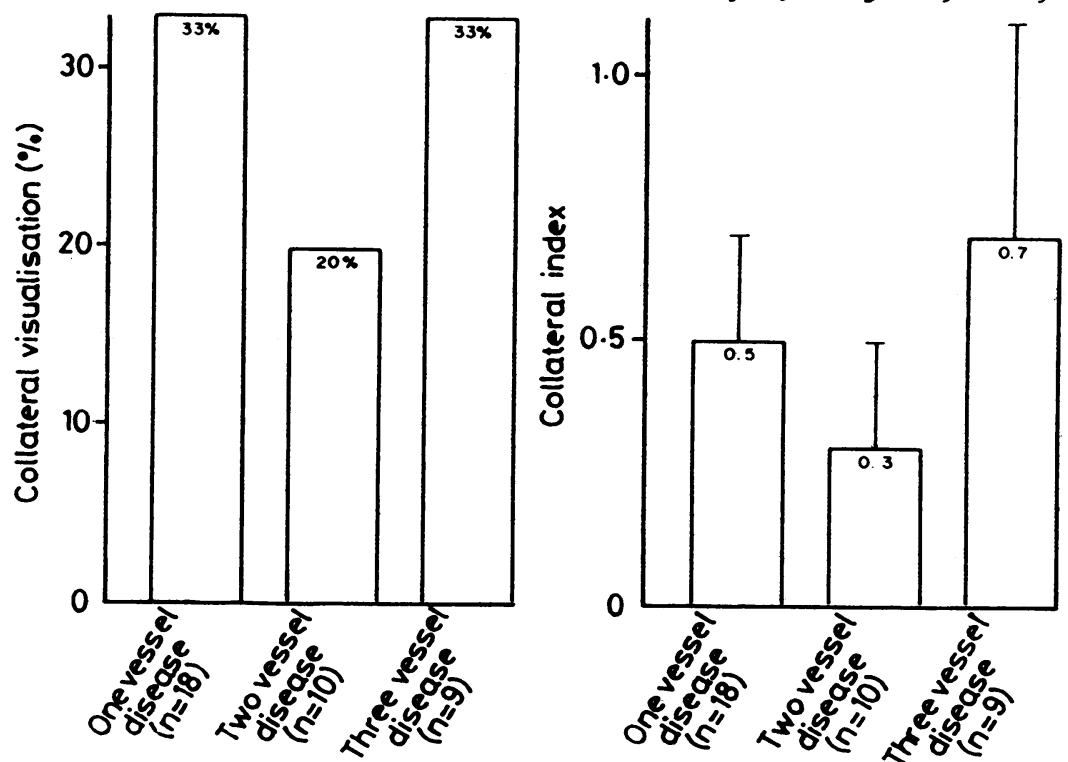

Fig 3 Collateral visualisation and collateral index in patients with the various degrees of severity of coronary vessel disease.

tor that was most strongly associated with the development of collateral vessels. Collateral channels were visualised in nine $(50 \%)$ of 18 patients with pre-infarction angina (group 1) and in only two $(11 \%)$ of 19 patients without (group 2$)(p<0.05)$. The collateral index was significantly higher in group $1(0.8(0.2))$ than in group $2(0.2(0.3))$ (fig 1$)$.

The site of infarction did not significantly affect the proportion of patients showing collateral opacification. This was seen in seven $(33 \%)$ of the 21 patients with anterior infarction and in four $(25 \%)$ of the 16 with infarction of other sites. The collateral index was also similar in both groups $(0.5(0.2)$ vs 0.4 $(0 \cdot 2)$ ) (fig 2).

The proportion of patients in whom collateral flow was visualised was similar in groups with one vessel disease $(6 / 18,33 \%)$, two vessel disease $(2 / 10,20 \%)$, and three vessel disease $(3 / 9,33 \%)$. These groups also had similar collateral indexes $(0.5(0.2), 0.3$ $(0.2)$, and $0.7(0.4)$ respectively) (fig 3$)$.

\section{Discussion}

Some patients with occlusion of one or more of major coronary arteries do not experience myocardial ischaemia at rest because an adequate blood supply is maintained through well developed collateral channels. ${ }^{10}$ Other groups have emphasised the importance of collaterals in preserving left ventricular function after acute myocardial infarction. ${ }^{31112}$ Little is known, however, about collateral development at the onset of myocardial infarction.
There are conflicting reports on the relation $>$ between preceding angina and of the prevalence of collateral development after acute myocardiak infarction. ${ }^{34}$ Aygen reported that 70 out of $81 \frac{\overline{0}}{0}$ patients with the history of pre-infarction angina hade adequate collaterals, whereas only five of 19 patientso without pre-infarction angina showed collaterals. 4 Aygen may have seen more collaterals in his patients 3 than we saw in our group because the intervale between the onset of acute infarction and coronary? angiography was longer than in our study. ${ }^{9}$

We examined our patients by coronary arteriography within six hours of the development of severe anterior chest pain. Schaper et al demon-3 strated that it takes at least eight hours for cells in thei collateral vessels to start proliferating after the abrupt occlusion of canine coronary arteries. ${ }^{13}$ Therefore, it seems unlikely that collateral channels will develop if severe myocardial ischaemia is shorto lived. Thus it seems reasonable to suggest a relation between pre-existing myocardial ischaemia and the extent of collateral circulation during the acute phasen of myocardial infarction.

Williams et al also reported that five of nine patients with pre-infarction angina had adequate collaterals whereas only one of 11 patients without angina before infarction had angiographic evidences of adequate collaterals. ${ }^{3}$ Although the frequency with which collaterals were visualised in their studyö resembled our findings, their results must be inter-क्ष preted with caution because the interval of 15 daysi from the onset of acute infarction to cardiac cath- 
eterisation may well have permitted collateral development. On the other hand, 11 of their 20 patients had subtotal obstruction of the infarct related coronary artery. When the collateral circulation is assessed in the absence of total obstruction of the diseased coronary artery, collateral function may be underestimated. Indeed, Rentrop et al showed that the visualisation rate of collateral vessels was substantially increased by the complete occlusion of the coronary artery by an angioplasty balloon. ${ }^{6}$ These two factors will have had opposing effects on collateral visualisation in the study of Williams et al. ${ }^{3}$

In our study half of the patients with preinfarction angina had well developed collaterals. In those who did not, stenosis of an artery supplying the collateral vessel could have reduced the pressure gradient across the collateral network and hence collateral perfusion. This was not the case in these patients, however, because there were no differences in the severity of coronary atherosclerosis between patients with and without collaterals. Moreover, the frequency of angiographically displayed collaterals was similar for anterior infarcts and infarcts of other sites. Consequently, these variations in developing collaterals appear to be related to disparities in individual responsiveness to ischaemic stimulation or differences in total amount of myocardial ischaemia.

Seventeen of 19 patients without pre-infarction angina had no angiographically visualised collaterals. The prognosis of patients without collaterals at the time of acute myocardial infarction is worse than that in those with well developed collaterals. ${ }^{31112}$ Accordingly, the prevention of the factors initiating myocardial infarction must be of particular importance in managing patients with minimum ischaemic symptoms.

\section{References}

1 Litvak J, Siderides LE, Vineberg AM. The experimental production of coronary artery insufficiency and occlusion. Am Heart $\mathcal{f}$ 1957;53:505-18.
2 Elliot EC, Jones EL, Bloor CM, Leon AS, Gregg DE. Day-to-day changes in coronary hemodynamics secondary to constriction of circumflex branch of left coronary artery in conscious dogs. Circ Res 1968;22:237-50.

3 Williams DO, Amsterdam EA, Miller RR, Mason DT. Functional significance of coronary collateral vessels in patients with acute myocardial infarction: relation to pump performance, cardiogenic shock and survival. Am ₹ Cardiol 1976;37:345-51.

4 Aygen $M$. Collateral circulation and regional myocardial function. Bibl Cardiol 1977;36:136-40.

5 Gregg DE. Coronary circulation in health and disease. Philadelphia: Lea and Febiger, 1950:187-202.

6 Rentrop KP, Cohen M, Blanke H, Phillips RA. Changes in collateral channel filling immediately after controlled coronary artery occlusion by an angioplasty balloon in human subjects. $\mathcal{F} \mathrm{Am}$ Coll Cardiol 1985;5:587-92.

7 Pasyk S, Bloor CM, Khouri EM, Gregg DE. Systemic and coronary effects of coronary artery occlusion in the unanesthetized dog. Am $\mathcal{F}$ Physiol 1971;220: 646-54.

8 Bloor CM, White FC. Functional development of the coronary collateral circulation during coronary artery occlusion in the conscious dog. Am $\mathcal{F}$ Pathol 1972;67:483-500.

9 Ohgitani N. Time-delay of visualisation of coronary collaterals after the onset of myocardial infarction. Ipn Circ F 1977;41:1277-8.

10 Freedman SB, Dunn RF, Bernstein L, Morris J, Kelly DT. Influençe of coronary collateral blood flow on the development of exertional ischemia and $Q$ wave infarction in patients with severe single-vessel disease. Circulation 1985;71:681-6.

11 Rogers WJ, Hood WP, Mantle JA, et al. Return of left ventricular function after reperfusion in patients with myocardial infarction: importance of subtotal stenoses or intact collaterals. Circulation 1984;69:338-49.

12 Saito $Y$, Yasuno $M$, Ishida $M$, et al. Importance of coronary collaterals for restoration of left ventricular function after intracoronary thrombolysis. Am $\mathcal{Y} \mathrm{Car}$ diol 1985;55:1259-63.

13 Schaper W, De Bravander M, Lewi P. DNA synthesis and mitoses in coronary collateral vessels of the dog. Circ Res 1971;28:671-9.

14 Austen WG, Edwards JE, Frye RL, et al. A reporting system on patients evaluated for coronary artery disease. Circulation 1975;51 (suppl IV):IV-5-40. 